\title{
Economic survey to support control decision for old world bollworm on processing
}

\section{tomatoes}

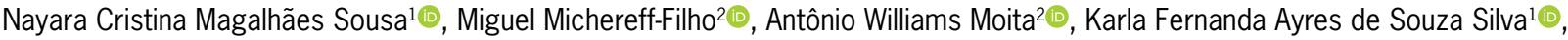 \\ Paloma Alves Silva2 ${ }^{2}$, Jorge Braz Torres ${ }^{1 *}$ (i)
}

${ }^{U}$ Universidade Federal Rural de Pernambuco - Depto. de Agronomia, R. Dom Manoel de Medeiros, s/n - 52171-900 Recife, PE - Brasil.

Embrapa Hortaliças - Lab. de Entomologia, C.P. 218 70359-970 - Brasília, DF - Brasil.

*Corresponding author <jorge.torres@ufrpe.br>

Edited by: Alberto Soares Corrêa

Received October 19, 2019

Accepted March 21, 2020
ABSTRACT: Helicoverpa armigera (Hübner) regularly requires quick deployment of control practices due to its potential of causing yield loss of processing tomatoes. The monitoring of $H$. armigera adults using stick traps lured with sex pheromone was correlated to egg densities, larvae, and percentage of damaged fruits, aiming to subsidize control decisions only using the number of males caught in the traps since surveying pest stages or damaged fruits is laborious and costly. Surveys were carried out on 11 tomato fields (ca. 80 to 120 hectares each) for processing during the 2015 and 2016 crop seasons. The survey was initiated at the flowering stage with traps set up along the field borders $100 \mathrm{~m}$ distant each. Evaluations of adult male capture in the traps were conducted twice a week for 14 and 10 weeks during the 2015 and 2016 seasons, respectively. Simultaneously, 70 tomato plants were fully inspected for eggs, larvae, and damaged fruits per area using a rate of 10 plants per point of trap setting in each area. Overall capture of male moths correlated to subsequent eggs, larvae, and damaged fruits. Based on the outcome of the regression analysis between male moths captured and percentage of damaged fruits, the control decision is suggested when three to six male moths are captured per trap during one week. The monitoring of adults using pheromone traps help deploy chemical or biological control methods to restrain $\mathrm{H}$. armigera population reaching economic threshold levels.

Keywords: Heliothinae, sex pheromone, tomato pests, monitoring

\section{Introduction}

The Old World bollworm, Helicoverpa armigera (Hübner) (Lepidoptera: Noctuidae), was recorded damaging various crops in Brazil in 2013 (Czepak et al., 2013; Specht et al., 2013). Afterwards, there was a quick dispersion through several states in Brazil and across the South and Central American regions (Murúa et al., 2014; Kriticos et al., 2015; Castiglioni et al., 2016). Hence, it became a major issue for integrated pest management (IPM) already established, requiring new protocols for monitoring and spraying field crops. In tomato crops, $H$. armigera has been considered as a major pest, as it damages leaves, and mainly flowers and fruits throughout tomato-producing areas in Brazil (Czepak et al., 2013; Pratissoli et al., 2015).

Any successful pest management requires data about the biology and ecology of the target pest to subsidize control practices. Data on the biology of $H$. armigera, including tomato as the host plant, has been generated (Kouhi et al., 2014; Herald and Tayde, 2018); however, control decision under tomato field infestation requires monitoring and knowledge about its response to local environmental conditions and relationship with plant phenology. Because of the recent record of $H$. armigera in Brazil infesting tomato fields, control decisions were taken empirically based on local observations or data generated in other countries. In spite of other control measures possible, insecticide applications prevail against recently introduced pest species (Vivan et al., 2016). Besides damages to the environment and increases in production costs, intensive use of insecticides might result in resistance of $H$. armigera to different active ingredients, as recorded in other countries (http:// www.pesticideresistance.org). Therefore, adopting pest monitoring and considering the injury levels for making control decisions can optimize the mitigation of such problems. In this context, the use of traps containing synthetic sex pheromone has been successfully applied to support control decisions (Ahmed and Khalique, 2002; Pal et al., 2014). According to Izquierdo (1996), traps with synthetic sex pheromone aim to obtain rapid information about the pest presence in the field crop, determine population fluctuation over time irrespective of the host crop phenology and within intercropping periods (Neves et al., 2018).

In this work, we correlated the number of $H$. armigera male adults captured in pheromone traps with eggs, larvae, and tomato fruit damage to subsidize control decision to spray processing tomato fields. To reach this goal, traps lured with synthetic sex pheromone of $H$. armigera were set up during two growing seasons (2015 and 2016) covering 11 commercial growing tomato fields. Further, we estimated the relationship between the number of captured moths and subsequent larvae infestation levels and fruit damage. 


\section{Materials and Methods}

\section{Study sites}

The study was carried out using 11 processing tomatoes commercial fields irrigated by pivot in Cristalina, Goiás, Brazil $\left(16^{\circ} 21^{\prime} \mathrm{S}, 47^{\circ} 32^{\prime} \mathrm{W}\right.$, altitude $922 \mathrm{~m}, 16^{\circ} 18^{\prime} \mathrm{S}, 47^{\circ} 37^{\prime} \mathrm{W}$, altitude $\left.945 \mathrm{~m}\right)$, in 2015 and 2016, respectively. The processing tomato cultivars were AP533, TY2006, and H9553. The tomato growing seasons during these two years were from Apr to Aug 2015 and from June to Sept 2016. The fields were cultivated under common agricultural practices for growing processing tomatoes in the region, adopted by the grower, including pesticide applications for crop phytosanitary management.

\section{Relationships of male Helicoverpa armigera captured by pheromone traps and crop loss}

We used Delta ${ }^{\circledR}$ traps lured with synthetic sex pheromone of $H$. armigera. Each trap received a rubber septum impregnated with sex pheromone [ $500 \mu \mathrm{g}$ of the mixture 10:1 of (Z)-11-hexadecenal and (Z)-9-hexadecenal]. The sex pheromone-lured traps were set up $100 \mathrm{~m}$ from each other at the border of the fields (Guerrero et al., 2014), accounting for seven traps covering a portion on each 11 field delimited by the area covered by a pivot. The period of monitoring lasted 14 and 10 weeks with continuous trap run during 2015 and 2016, respectively. The traps were set up in the fields 40 days after seedling transplanting with the plants entering the flowering stage. The evaluations were run twice a week by counting the number of adult moths captured per trap. Simultaneously with trap evaluation, we also recorded the number of eggs and larvae per plant, as well as damaged (bored) fruits. The density of eggs, larvae, and damaged fruits per plant were obtained by fully inspecting 10 plants per point of respective traps accounting for 70 plants evaluated per area mixing random plants evaluated at the border up to 5 $\mathrm{m}$ from the traps toward the field center, and in the center of the area. Periodically, larvae were collected from these areas to produce adults for other studies and adults from traps at peak of occurrence were checked for species identification through the analysis of the mitochondrial DNA region containing the cytochrome oxidase $\mathrm{C}$ subunit I (COI) gene as described in Michereff-Filho et al. (2018), with our collections resulting in $100 \%$ for $H$. armigera.

Data on male moths captured per trap were rated per trap and subjected to analysis of correlation (PROC CORR) with the infestation level of $H$. armigera (density of eggs and larvae per plant) and with the losses per plant as the percentage of damaged fruits per plant rated from 10 plants inspected per point of trap setting. Furthermore, the average number of eggs, larvae, and damaged fruits per week (n) were correlated with the number of males captured per trap in the week (n) of the survey, one week $(n-1)$, and two weeks before $(n-2)$. In order to put the survey data on adults into a recommended intervention procedure, we took into account $5 \%$ damaged fruits accepted by the industry as the standard of quality. Thus, the trap index for the decision-making for $H$. armigera control, a regression analysis (PROC GLM) of trapped male moths capture was performed as a function of the percentage of accumulated bored fruits. To correct overdispersion distribution, data were transformed into $\log _{10}(\mathrm{x}+1)$ and submitted to regression (PROC GLM) and correlation (PROC CORR) analyses using the SAS Software (Statistical Analysis System, v. 9.0). The results obtained were used to predict infestation and yield losses aiming to recommend control $H$. armigera infesting processing tomato fields.

\section{Results}

\section{Relationships of male Helicoverpa armigera capture by pheromone traps and crop loss.}

Data from male moths captured per trap highlight the predominant period of $H$. armigera activity in processing tomato fields during two growing seasons. During the 2015 season with surveys run from Apr to Aug, the greater moth captures occurred in the $19^{\text {th }}$ and $30^{\text {th }}$ weeks of the year corresponding to $13^{\text {th }}$ May and $26^{\text {th }}$ July, respectively (Figure 1). Within this same season, higher densities of eggs per plant were observed in the $21^{\text {st }}$ and $27^{\text {th }}$ weeks corresponding to the beginning of June and July (Figure 1). Following egg infestation, peaks of larvae infestation occurred in the $21^{\text {st }}$ and $28^{\text {th }}$ weeks of 2015, corresponding to $28^{\text {th }}$ May and $9^{\text {th }}$ July, respectively. The percentage of damaged fruits were greater in the $18^{\text {th }}$ and $30^{\text {th }}$ weeks of 2015 , corresponding to the $4^{\text {th }}$ week of Apr and the $2^{\text {nd }}$ week of July (Figure 1 ).

During the season 2016, surveys were run from the beginning of June to the end of Aug, male moths of $H$. armigera exhibited major occurrence during the $24^{\text {th }}$ (14 June) and $34^{\text {th }}$ (25 Aug) weeks of the year (Figure 2). Greater egg densities were observed in the $24^{\text {th }}$ week (14 June), in the same week of the first peak of moths capture in the traps. Subsequently, predominance of larvae in the fields occurred during two major periods corresponding to the $25^{\text {th }}$ (24 June) and $32^{\text {nd }}(12 \mathrm{Aug})$ weeks of the year, respectively. Finally, the peak of damaged fruits occurred during the $31^{\text {st }}$ and $34^{\text {th }}$ weeks, both in Aug (Figure 2).

During the two surveyed seasons, the mean number of male moths captured varied from 0 to 4.04 moths*(trap*night). The mean number of eggs and larvae per 10 plants through both seasons varied from 0 to 3.14 eggs, and 0 to 3.07 larvae, respectively. The weekly percentage means of damaged fruits during the two seasons varied from 0 to $12 \%$.

The correlations analysis considering egg densities, larvae and percentage of damaged fruits as a function of adult male captured in the pheromone traps run during the two growing seasons resulted in correlation for 11 out of 18 outcomes (Table 1). The results support the hypothesis that captures of male moths in pheromone traps indicate a further presence of eggs and larvae in 


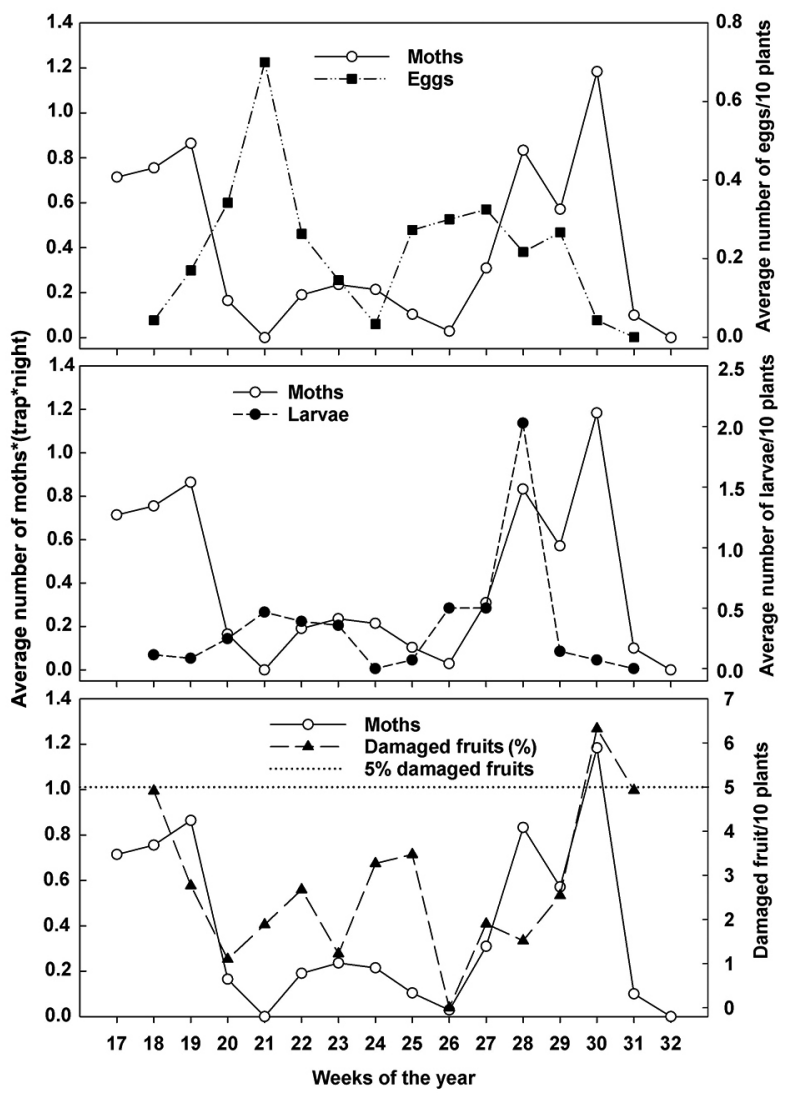

Figure 1 - Average of male moths of Helicoverpa armigera captured in traps lured with synthetic sex pheromone, eggs, larvae and percentage of damaged fruits during surveyed season 2015. Note: Y2-axis has a different scale due to differences in the values. Dotted lines indicate economic threshold levels for average percentage of damaged fruits per 10 plants according to captured male moths in pheromone traps.

Table 1 - Correlation coefficients ( $r$ ) between captures of Helicoverpa armigera males in traps, level of larvae infestation, and damaged fruits of processing tomatoes during seasons 2015 and 2016.

\begin{tabular}{lccc}
\hline \multirow{2}{*}{ Number of captured moths } & \multicolumn{3}{c}{ Correlation coefficients $(r)^{1}$} \\
\cline { 2 - 4 } & No. of eggs No. of larvae Damaged fruits (\%) \\
\hline \multirow{3}{*}{ Surveyed week (n) } & -0.048 & $0.164^{*}$ & 0.060 \\
One week before (n-1) & -0.069 & 0.115 & -0.061 \\
Two weeks before (n-2) & $-0.200^{*}$ & $-0.215^{*}$ & $0.198^{*}$ \\
\hline & \multicolumn{3}{c}{ Season 2016 } \\
Surveyed week (n) & $0.387^{* *}$ & $0.188^{*}$ & $0.293^{* *}$ \\
One week before (n-1) & 0.125 & $0.187^{*}$ & $0.327^{* *}$ \\
Two weeks before (n-2) & 0.063 & $0.228^{*}$ & $0.297^{*}$ \\
\hline
\end{tabular}

${ }^{1}$ Data transformed into $\log _{10}(x+1) .{ }^{*} p<0.05$, and ${ }^{* *} p<0.0001$.

the field, followed by percentage of fruit damage despite of low correlation values. In the 2015 season, egg densities and the capture of male moths did not show a correlation $(p>0.05)$ in the week of survey $(\mathrm{n})$ and

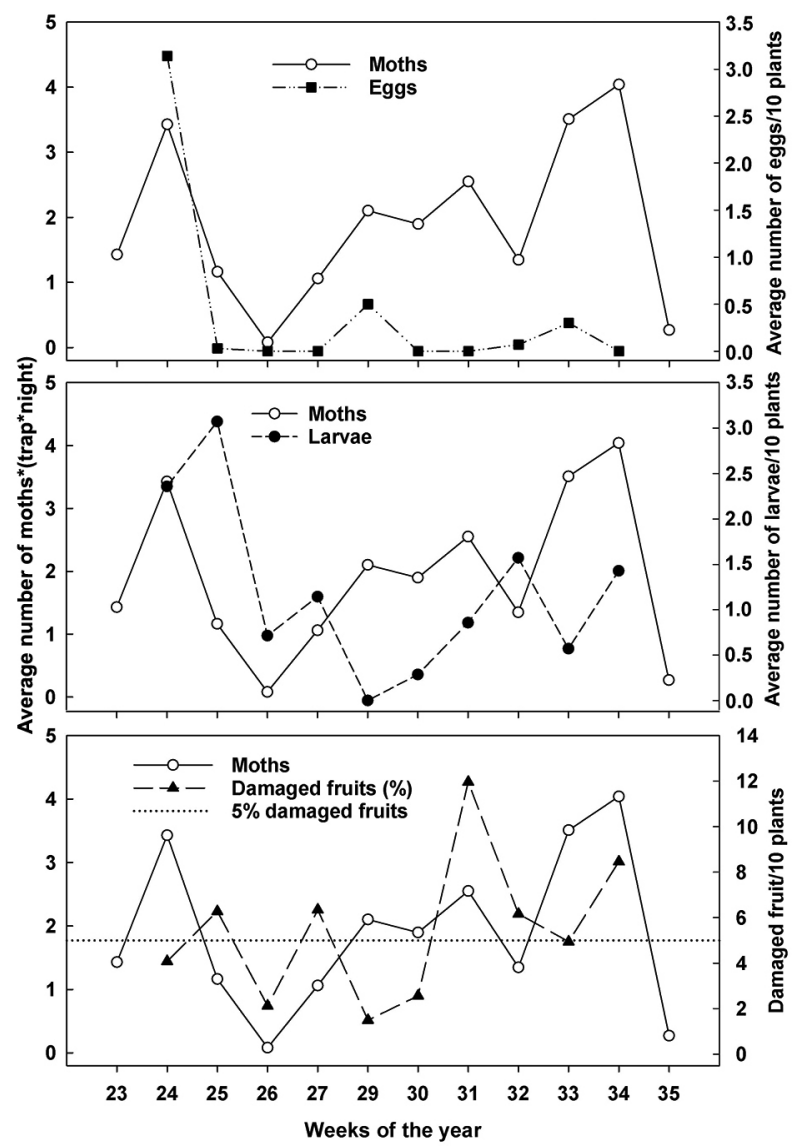

Figure 2 - Average of male moths of Helicoverpa armigera captured in traps lured with synthetic sex pheromone, eggs, larvae and percentage of damaged fruits during surveyed season 2016. Note: Note: Y2-axis has a different scale due to differences in the values. Dotted lines indicate economic threshold levels for average percentage of damaged fruits per 10 plants according to captured male moths in the pheromone traps.

one week before (n-1), while it was negatively correlated two weeks before (n-2). In 2016, these data turned out positive correlations in the week of survey $(p<0.001)$. It is worth mentioning, however, that in 2016, there was a greater moth capture compared to 2015. Furthermore, male capture and infestation of larvae were correlated positively in both seasons (Table 1).

Regarding the specific pairs of correlations, there is a lack of significance for larvae infestation in the week of survey (n) and male capture two weeks before (n-2) in 2015, as expected, differently from 2016, when these data correlated positively. Furthermore, in the 2015 season, correlations were observed between adult captures and number of larvae in the week surveyed, and number of eggs, number of larvae, and damaged fruits with male captures two weeks before (Table 1). On the other hand, in the 2016 season, the number of male moths captures was correlated with damaged fruits in 
the week of the survey, and with captures one and two weeks earlier.

The number of larvae recorded and egg densities recorded in the week of the survey, one and two weeks before they correlated positively for both seasons (Table $2)$. Nonetheless, the number of eggs recorded was correlated with the percentage of damaged fruits in the week of the survey and two weeks before in 2016 (Table 2). Furthermore, a positive correlation between the density of larvae and damaged fruits was achieved for the week of the survey (n) (Table 2).

The accumulated number of male moths captured per trap and the percentage of damaged fruits were highly correlated in both years (Figure 3). The mean number of male moths captured per trap in the 2015 and

Table 2 - Correlation coefficients ( $r$ ) between densities of eggs and larvae of Helicoverpa armigera and damaged fruits of processing tomatoes during seasons 2015 and 2016.

\begin{tabular}{|c|c|c|}
\hline Number of eggs ${ }^{1}$ & Number of larvae ${ }^{1}$ & Damaged fruits (\%) \\
\hline \multicolumn{3}{|c|}{ Season 2015} \\
\hline Suveyed week (n) & $0.205^{\star}$ & -0.026 \\
\hline One week before (n-1) & $0.172^{*}$ & 0.072 \\
\hline Two weeks before (n-2) & $0.224^{*}$ & 0.055 \\
\hline \multicolumn{3}{|c|}{ Season 2016} \\
\hline Surveyed week (n) & $0.318^{* *}$ & $-0.156^{\star}$ \\
\hline One week before $(n-1)$ & $0.177^{\star}$ & 0.094 \\
\hline Two weeks before (n-2) & $0.346^{* *}$ & $0.242^{*}$ \\
\hline Number of larvae & \multicolumn{2}{|c|}{ Damaged fruits (\%) } \\
\hline \multicolumn{3}{|c|}{ Season 2015} \\
\hline Surveyed week (n) & \multicolumn{2}{|l|}{0.120} \\
\hline One week before $(n-1)$ & \multicolumn{2}{|l|}{0.121} \\
\hline Two weeks before ( $\mathrm{n}-2)$ & -0.030 & \\
\hline \multicolumn{3}{|c|}{ Season 2016} \\
\hline Surveyed week (n) & \multicolumn{2}{|l|}{$0.407^{* *}$} \\
\hline One week before (n-1) & \multicolumn{2}{|l|}{-0.100} \\
\hline Two weeks before $(n-2)$ & \multicolumn{2}{|l|}{-0.074} \\
\hline
\end{tabular}

Data transformed into $\log _{10}(x+1) .{ }^{*} p<0.05$, and ${ }^{* *} p<0.0001$.

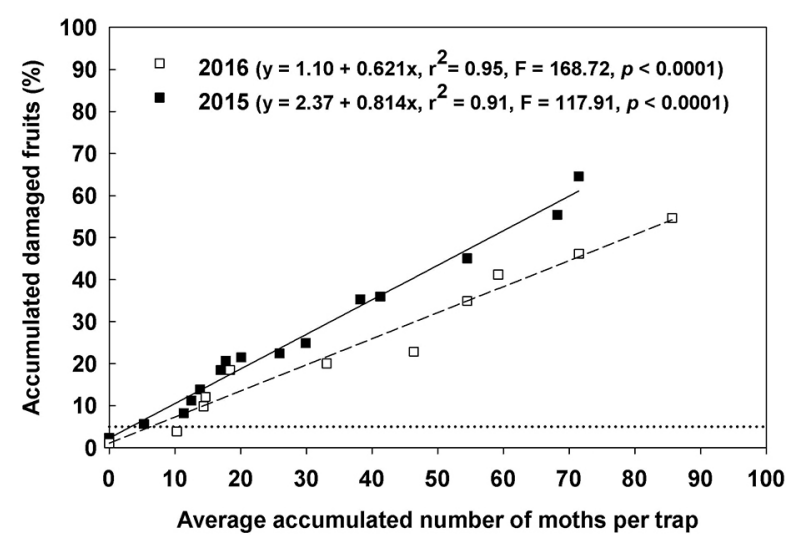

Figure $\mathbf{3}$ - Weekly relationship between the accumulated means of male moths of Helicoverpa armigera captured per trap and accumulated percentages of damaged fruits during seasons 2015 and 2016. Dotted line indicates economic threshold level.
2016 seasons during 113 and 77 days of continuous trap run resulted in 0.63 and 1.10 adults*(trap*night). These numbers of capture were sufficient to produce economic crop losses.

Control decision recommended by the tomato processing industry is $5 \%$ of damaged fruits by $H$. armigera. Thus, based on the regression analysis regarding the accumulated number of moths captured as a function of the percentage of damaged fruits per trap weekly, we conclude that the capture of three to six male moths per trap per week reached the control decision in 2015 and 2016 seasons, respectively (Figure 3).

\section{Discussion}

The fluctuation of $H$. armigera determined in this study used sex pheromone traps during two growing seasons in large commercial processing tomato fields and depicted variation in the number of male moths captured and their correlations with damaged fruits, thereby, showing the potential of pest infestation prediction and support for control tactics. This decision, however, varies in time regarding the infestation, and its prediction is possible based on the number of male moths caught in traps. Variation in adult fluctuation over time within the growing season is expected because it depends on host susceptibility or host stage (e.g. tomato flowering and fruiting stages), besides biotic and abiotic factors in the region. Malik et al. (2003) reported that temperature and humidity affected the development and distribution of $H$. armigera. Furthermore, Sharma et al. (2012) found a positive correlation of the maximum and minimum temperatures with captures of male moths in the pheromone traps and infestation of larvae in chickpea fields, while relative humidity correlated negatively with these variables.

Insect development and reproduction are directly affected by variations in temperatures, which produce correlations in long time data series; however, hinder identification of correlations within short periods, such as specific crop phenology stage due to numerous influencing variables. Yet, there is an additional component regarding $H$. armigera that is the polyphagous behavior of this species. Although tomato is the preferred host by $H$. armigera (Ashfaq et al., 2003), the presence of other hosts sharing crop landscapes poses as an impact to determine OWB in tomato fields (Zalucki et al., 1986; Rhino et al., 2014). According to Firempong and Zalucki (1991), $H$. armigera was detected in the environment in the absence of the tomato crop. Nevertheless, our data resulted in 11 significant correlations out of 18 correlations possible considering captures of male moths in pheromone traps. These data support the technique of surveying tomato fields for $H$. armigera infestation and making control decisions. It is also worth highlighting that the use of pheromone traps in these large commercial tomato fields is accepted by growers because the method simple and easy to gather data in support of control decisions. 
The data indicate greater egg densities in tomato plants in the $21^{\text {st }}$ week (May) in 2015 and in the $24^{\text {th }}$ week (July) in 2016, coinciding with the flowering stage peak in the regions. During Sept, when tomato fields entered the maturation stage, the data matched the reduction in the number of males captured in the traps and thereafter reducing egg counts on plants. This is an expected outcome for $H$. armigera because there is a predominance of adult OWB attraction for tomato plants due to crop phenology (Firempong and Zalucki, 1991), as plants in the flowering and fruiting stages are more attractive to egg-laying (Zalucki et al., 1986; Cameron et al., 2001). Accurate knowledge of $H$. armigera adult activity in the crop field using pheromone traps facilitates egg availability in the field. This supports, beyond the control decision, deployment of the control practices to attain pest population reduction, such as releasing of the egg parasitoid Trichogramma sp. (Zuim et al., 2017), and biological insecticides application aiming to control newly hatched larvae, such as nucleopolyhedrovirus (NPV) and Bacillus thuringiensis commercial formulations (Vivan et al., 2017).

Capture of the male moths of $H$. armigera was followed by infestation of larvae and damaged fruits, especially during 2016, when there was greater activity of the pest in the areas, corroborating the data from Kehat et al. (1982) and Srivastava and Srivastava (1995). The authors reported that, when capture of OBW male moths in the pheromone traps increased, there was a subsequent increase in the number of eggs and larvae in cotton and chickpea fields. These correlations support our data and their use for the control decision-making. According to our data, increases in captures of males were followed by an increasing infestation of larvae in both seasons (Figures 1 and 2). Furthermore, as expected, there was a delay from one to two weeks for infestation of larvae after increasing male captures. Again, deploying control practices against larvae should be applied within this interval to preclude the increase of large larvae and prevent fruit loss. The number of male moths caught per trap in the week of survey (n), one (n-1), and two weeks (n-2), correlated with egg density, infestation of larvae, and damaged fruits in the week of survey (n). Nyambo et al. (1989) and Pal et al. (2014) found similar dynamics for different crops. Therefore, data from other studies and crops support our data for processing tomato and validation of correlations with the number of male moths captured, indicating a subsequent infestation of larvae and damaged tomato fruits in the following weeks.

The quality standard for tomatoes depends on market destination (processing or fresh market) and consumers' demand. Tomato processing industries in India, New Zealand, and Spain determine what is acceptable between 2 and $5 \%$ of damaged fruits by $H$. armigera upon receipt at the industry (Cameron et al., 2001; Torres-Vila et al., 2003). To prevent this level of loss at harvesting, control decision should be taken when the maximum of fruits damaged reaches $5 \%$ during the fruiting stage in the field. This higher level of damage in the field compared to that accepted by industry is because the fruit attacked by larvae may continue to develop and reach the harvesting period, depending on damage magnitude. However, damaged fruits usually exhibit senescence, anticipation of the maturation process, and rotting by opportunistic microorganisms, resulting in drops of the attacked fruits before harvesting (Torres-Vila et al., 2003). Based on these situations, the fruits evaluated as damaged by OWB larvae during the growing stage of the crop may not be present at harvesting. Thus, it is possible to estimate the percentage of damaged fruits in the field, based on the number of $H$. armigera male moths caught in the pheromone traps.

The regression analysis between the percentage of damaged fruits and the number of male moths captured (Figure 3) shows that three to six males of $H$. armigera accumulated per trap during one week correspond to $\sim 5 \%$ of damaged fruits in our study conditions for processing tomatoes. Thus, this density of male moths captured suggests further adoption of control practices to reduce larval infestation in the field, preventing economic damage within one or two weeks. The number of moths caught in the trap and control decision may vary according to crop value. For instance, Prasad et al. (1993) recommended control measure against $H$. armigera infesting cotton fields when the number of males caught in the pheromone traps exceeds seven individuals* (trap*night).

The monitoring of $H$. armigera adopted in this study using pheromone traps allowed to define the moment of deploying control measures to reduce pest population or identify pest population densities since the level of yield loss does not justify the costs of control adoption. It also aimed to support rational control practices, such as programmed releases of parasitoids (Reddy and Manjunatha, 2000; Hussain et al., 2015; Zuim et al., 2017), application of biological insecticides against small larvae (Vivan et al., 2017) or recommending selected synthetic insecticides to promote reduction of larvae infestation irrespective of their age (Karar et al., 2017; Vivan et al., 2017). The findings provide useful information about $H$. armigera population densities and indices of male moths recorded per trap help make control decisions for processing tomato. In addition, these findings might stimulate further studies in other host crops of $H$. armigera sharing the same landscape, such as cotton, soybean, corn, chickpea, etc., and other regions in Brazil to support a rapid and economic decision against this pest.

\section{Acknowledgements}

This study was financed in part by the Coordination for the Improvement of Higher Education Personnel (CAPES) through the Program for Excellence Academic 
(PROEX CAPES) and the Program of Cooperation Academic - New Frontiers (PROCAD CAPES NF, and from Brazilian Agricultural Research Corporation (Embrapa Macroprograma 2 - Helicoverpa armigera - 02.13.14.006.00.00). We are grateful to Maurício Bakalarczyk and Adoilson (Grupo Sorgatto) and Lupersy Bassan (Agropecuária Agriter) for allowing us to access the fields and support during the field surveys. Thanks also to Moises Lopes Fernandes from Embrapa Vegetables for the assistance in the field surveys.

\section{Authors' Contributions}

Conceptualization: Sousa, N.C.M.; MichereffFilho, M.; Torres, J.B. Design of methodology: Michereff-Filho, M.; Sousa, N.C.M.; Torres, J.B. Data acquisition: Sousa, N.C.M.; Silva, K.F.A.S.; Silva, P.A. Data analysis: Moita, A.W.; Sousa, N.C.M.; Writing and editing: Sousa, N.C.M.; Michereff-Filho, M.; Torres, J.B.

\section{References}

Ahmed, K.; Khalique, F. 2002. Forecasting adult populations of Helicoverpa armigera on chickpea using pheromone trap. Pakistan Journal of Biological Sciences 5: 830-34.

Ashfaq, M.; Ahmad, K.J.; Ali, A. 2003. Morphophysical factors affecting consumption and coefficient of utilization of Helicoverpa armigera (Hübner). Pakistan Journal of Biological Sciences 3: 225-230.

Cameron, P.J.; Walker, G.P.; Herman, T.J.B.; Wallace, A.R. 2001. Development of economic thresholds and monitoring systems for Helicoverpa armigera (Lepidoptera: Noctuidae) in tomatoes. Journal of Economic Entomology 94: 1104-1112.

Castiglioni, E.; Perini, C.R.; Chiaravalle, W.; Arnemann, J.A.; Ugalde, G.; Guedes, J.V.C. 2016. First record of occurrence of Helicoverpa armigera (Hübner, 1808) (Lepidoptera: Noctuidae) in soybeans, in Uruguay. Agrociencia Uruguay 20: 31-35 (in Spanish, with abstract in English).

Czepak, C.; Albernaz, K.C.; Vivan, L.M.; Guimarães, H.O.; Carvalhais, T. 2013. First record of occurrence of Helicoverpa armigera (Hübner) (Lepidoptera: Noctuidae) in Brazil. Pesquisa Agropecuária Tropical 43: 110-113.

Firempong, S.; Zalucki, M.P. 1991. Host plant selection by Helicoverpa armigera (Lepidoptera: Noctuidae): the role of some herbivore attributes. Australian Journal of Zoology 39: 343-350.

Guerrero, S.; Brambila, J.; Meagher, R.L. 2014. Efficacies of four pheromone-baited traps in capturing male Helicoverpa (Lepidoptera: Noctuidae) moths in northern Florida. Florida Entomologist 97: 1671-1679.

Herald, K.P.; Tayde, A.R. 2018. Biology and morphology of tomato fruit borer, Helicoverpa armigera (Hübner) under Allahabad conditions. Journal of Entomology and Zoology Studies 6: 1734-1737.

Hussain, D.; Hussain, A.; Qasim, M.; Khan, J. 2015. Insecticidal susceptibility and effectiveness of Trichogramma chilonis as parasitoids of tomato fruit borer, Helicoverpa armigera. Pakistan Journal of Zoology 47: 1427-1432.
Izquierdo, J.I. 1996. Helicoverpa armigera (Hübner) (Lepidoptera: Noctuidae): relationship between captures in pheromone traps and egg counts in tomato and carnation crops. Journal of Applied Entomology 120: 281-290.

Karar, H.; Akhtar, M.S.; Khaliq, A.; Hussain, A.; Niazi, I.A.K.; Anees-ul-Hasnain, A.A.; Abdullah, A. 2017. Effect of novel insecticides on Helicoverpa armigera (Lepidoptera: Noctuidae) on seed crop of berseem (Trifolium alexandrinum L.) and their impact on seed yield. Pakistan Entomologist 39: 9-15.

Kehat, M.; Gothilf, S.; Dunkelblum, E.; Greenberg, S. 1982. Sex pheromone traps as a means of improving control programs for the cotton bollworm, Heliothis armigera (Lepidoptera: Noctuidae). Environmental Entomology 11: 727-729.

Kouhi, D.; Naseri, B.; Golizadeh, A. 2014. Nutritional performance of the tomato fruit borer, Helicoverpa armigera, on different tomato cultivars. Journal of Insect Science 14: 102.

Kriticos, D.J.; Ota, N.; Hutchison, W.D.; Beddow, J.; Walsh, T.; Tay, W.T.; Borchert, D.M.; Paula-Morais, S.V.; Czepak, C.; Zalucki, M.P. 2015. The potential distribution of invading Helicoverpa armigera in North America: is it just a matter of time? PLOS One 10: e0119618.

Malik, M.F.; Hussainy, S.W.; Munir, A.; Ali, L. 2003. Efficacy of synthetic pheromone for the control of Helicoverpa armigera in tomato. Asian Journal of Plant Sciences 2: 415-417.

Michereff-Filho, M.; Boiteux, M.E.N.F.; Boiteux, L.; Specht, A.; Moita, A.; Silva, K.F.A.; Silva, P.S.; Sousa, N.C.M. 2018. Survey of noctuid species in tomato crops in Brazil. Embrapa Hortaliças, Brasília, DF, Brazil. (Boletim de Pesquisa e Desenvolvimento, 159) (in Portuguese, with abstract in English).

Murúa, M.G.; Scalora, F.S.; Navarro, F.R.; Cazado, L.E.; Casmuz, A.; Villagrán, M.E.; Gastaminza, G. 2014. First record of Helicoverpa armigera (Lepidoptera: Noctuidae) in Argentina. Florida Entomologist 97: 854-856.

Neves, R.C.S.; Torres, J.B.; Barros, E.M.; Vivan, L.M. 2018. Boll weevil within season and off-season activity monitored using a pheromone-and-glue reusable tube trap. Scientia Agricola 75: 313-320.

Nyambo, B.T. 1989. Assessment of pheromone traps for monitoring and early warning of Heliothis armigera Hübner (Lepidoptera, Noctuidae) in the western cotton-growing areas of Tanzania. Crop Protection 8: 188-192.

Pal, S.; Chatterjee, H.; Senapati, S.K. 2014. Monitoring of Helicoverpa armigera using pheromone traps and relationship of moth activity with larval infestation on carnation (Dianthus caryophyllus) in Darjeeling Hills. Journal of the Entomological Research 38: 23-26.

Prasad, V.; Rambabu, L.; Reddy, G.P.V. 1993. An action threshold for Helicoverpa armigera $\mathrm{Hb}$. based on pheromone trap catches in cotton. Indian Journal of Plant Protection 21: 17-18.

Pratissoli, D.; Lima, V.L.; Pirovani, V.D.; Lima, W.L. 2015. Ocurrence of Helicoverpa armígera (Lepidoptera: Noctuidae) on tomato in the Espírito Santo state. Horticultura Brasileira 33: 101-105.

Reddy, G.V.P.; Manjunatha, M. 2000. Laboratory and field studies on the integrated pest management of Helicoverpa armigera (Hübner) in cotton, based on pheromone trap catch threshold level. Journal of Applied Entomology 124: 213-221. 
Rhino, B.; Grechi, I.; Marliac, G.; Trebeau, M.; Thibaut, C.; Ratnadass, A. 2014. Corn as trap crop to control Helicoverpa zea in tomato fields: importance of phenological synchronization and choice of cultivar. International Journal of Pest Management 60: 73-81.

Sharma, P.K.; Kumar, U.; Vyas, S.; Sharma, S.; Shrivastava, S. 2012. Monitoring of Helicoverpa armigera (Hubner) (Lepidoptera: Noctuidae) through pheromone traps in chickpea (Cicer arietinum) crop and influence of some abiotic factors on insect population. Journal of Environmental Science, Toxicology and Food Technology 1: 44-46.

Specht, A.; Sosa-Gómez D.R.; Paula-Moraes, S.V.; Yano, S.A.C. 2013. Morphological and molecular identification of Helicoverpa armigera (Lepidoptera: Noctuidae) and expansion of its occurrence record in Brazil. Pesquisa Agropecuária Brasileira 48: 689-692 (in Portuguese, with abstract in English). Srivastava, C.P.; Srivastava, R.P. 1995. Monitoring of Helicoverpa armigera (Hbn.) by pheromone trapping in chickpea (Cicer arietinum L.). Journal of Applied Entomology 119: 607-609.
Torres-Vila, L.M.; Rodríguez-Molina, M.C.; Lacasa-Plasencia, A. 2003. Testing IPM protocols for Helicoverpa armigera in processing tomato: egg-count- vs. fruit-count-based damage thresholds using Bt or chemical insecticides. Crop Protection 22: 1045-1052.

Vivan, L.M.; Torres, J.B.; Fernandes, P.L.S. 2017. Activity of selected formulated biorational and synthetic insecticides against larvae of Helicoverpa armigera (Lepidoptera: Noctuidae). Journal of Economic Entomology 101: 118-126.

Zalucki, M.P.; Daglish, G.; Firempong, S.; Twine, P.H. 1986. The biology and ecology of Heliothis armigera (Hübner) and $H$. punctigera (Wallengren) (Lepidoptera: Noctuidae) in Australia: what do we know? Australian Journal of Zoology 34: 779-814.

Zuim, V.; Rodrigues, H.S.; Pratissoli, D.; Torres, J.B.; Fragoso, D.F.M.; Bueno, R.C.O.F. 2017. Age and density of eggs of Helicoverpa armigera influence on Trichogramma pretiosum parasitism. Acta Scientiarum Biological Science 39: 513-520. 